\title{
Pengaruh Kepribadian Narsistik terhadap Perilaku Non-Suicidal Self-Injury pada Remaja Broken Home
}

\author{
DEBBY SHIRA CHINTIA DEWI \& ATIKA DIAN ARIANA* \\ Departemen Psikologi Klinis dan Kesehatan Mental, Fakultas Psikologi Universitas Airlangga
}

\begin{abstract}
ABSTRAK
Penelitian ini bertujuan untuk mengetahui adakah pengaruh dari kepribadian narsistik terhadap perilaku non-suicidal self-injury (NSSI) pada remaja yang mengalami broken home. Kepribadian narsistik memiliki dua konstruk yaitu grandiose dan vulnerability narcissism. Partisipan dalam penelitian ini merupakan remaja yang mengalami kondisi broken home usia 12-22, dengan bentuk broken home seperti orang tua yang telah bercerai, orang tua yang tidak hadir, hilangnya peran dari anggota keluarga, dan keluarga yang tidak harmonis. Total partisipan dalam penelitian ini adalah 135 orang. Alat ukur yang digunakan adalah Pathological Narcissism Inventory yang dikembangkan oleh Pincus dan kawankawan dan Inventory of Statements About Self-injury yang dikembangkan oleh Glenn dan Klonsky. Analisis data menggunakan teknik korelasi dan regresi linear sederhana. Hasil analisis data menunjukkan bahwa kepribadian narsistik berpengaruh secara signifikan terhadap perilaku NSSI $(B=0,137 ; p=0,00)$. Besar pengaruh kepribadian narsistik untuk menjelaskan variasi dari perilaku NSSI pada remaja broken home adalah sebesar 11,8\% dengan korelasi antar variabel bersifat positif.
\end{abstract}

Kata kunci: broken home, kepribadian narsistik, non-suicidal self-injury

\section{ABSTRACT}

This study aims to determine whether there is an effect of narcissistic personality on non-suicidal selfinjury (NSSI) behavior in adolescents who experience broken home. Narcissistic personality has two constructs, namely grandiose and vulnerability narcissism. Participants in this study were adolescents who experienced broken home aged 12-22, with broken home conditions as divorced parents, absent parents, loss of roles from family members, and disharmonious families. The total participants in this study were 135 people. The measuring instrument used is the Pathological Narcissism Inventory developed by Pincus et al. and the Inventory of Statements About Self-injury developed by Glenn and Klonsky. Data analysis used simple linear correlation and regression techniques. The results of data analysis showed that narcissistic personality had a significant effect on NSSI behavior $(B=0.137$; $\mathrm{p}=0.00$ ). The influence of narcissistic personality to explain the variation of NSSI behavior in broken home adolescents is $11.8 \%$ with a positive correlation between variables.

Keywords: broken home, narcissistic personality, non-suicidal self-injury

Buletin Penelitian Psikologi dan Kesehatan Mental (BRPKM), 2021, Vol. 1(1), 87-95

*Alamat korespondensi: Fakultas Psikologi Universitas Airlangga, Kampus B Universitas Airlangga Jalan Airlangga 4-6 Surabaya 60286. Surel: atika.ariana@psikologi.unair.ac.id 
sehingga penggunaan, distribusi, reproduksi dalam media apapun atas artikel ini tidak dibatasi, selama sumber aslinya disitir dengan baik.

\section{PE N D A H U L U A N}

Keluarga merupakan salah satu pihak terpenting dalam tumbuh kembang anak, terutama pada masa remaja. Bimbingan, dukungan, serta kasih sayang perlu diberikan agar anak tetap tumbuh dengan baik. Keluarga dengan orang tua lengkap dapat membimbing anaknya sesuai dengan peran masing-masing. Namun, tidak sedikit keluarga yang berkonflik dan berujung pada masalah lain, seperti kekerasan dalam rumah tangga (KDRT) baik kekerasan verbal maupun fisik, ketidakhadiran orang tua dan juga perceraian. Willis (2015) menyampaikan bahwa istilah broken home dapat diartikan sebagai keluarga yang retak yaitu hilangnya perhatian keluarga atau kurangnya kasih sayang dari orang tua yang disebabkan beberapa hal, bisa karena perceraian sehingga anak hanya tinggal bersama salah satu orang tuanya. Keluarga broken home juga dapat dilihat dari ketidakharmonisan antara orang tua, anak angkat, pengasuhan di panti atau kerabat, kecanduan narkoba atau penyakit jiwa di antara salah satu atau kedua orang tua, atau penolakan anak oleh orang tuanya (Schaller \& Schmidtke, 1988). Meskipun istilah broken home hanya diterapkan pada keluarga yang secara struktural tidak lengkap, sejumlah aspek juga perlu dibedakan dengan cermat, seperti orang tua yang tidak hadir, alasan ketidakhadiran, durasi dan titik awal ketidakhadiran, dan situasi yang dihasilkan (Lösel, 1971; dalam Schaller \& Schmidtke, 1988).

Perilaku yang terlihat dari anak dengan latar belakang broken home beragam. Astriyani dan kawankawan (2018) menemukan bahwa siswa dari keluarga broken home cenderung memiliki motivasi belajar yang rendah dari dalam maupun luar dirinya, sehingga memengaruhi capaian prestasi belajar mereka yang juga rendah. Zatti dan kawan-kawan (2017), menemukan kasus trauma pada anak yang berujung pada percobaan bunuh diri dilakukan karena berbagai faktor, termasuk kondisi broken home salah satunya. Percobaan bunuh diri dilakukan oleh $70 \%$ wanita dan $44 \%$ laki-laki pada usia sebelum 20 tahun, dengan faktor yang paling sering menjadi alasan adalah kondisi broken home dan pelecehan atau kekerasan seksual di masa kecil. Ditemukan juga pada penelitian milik Angst dan kawan-kawan (2014) bahwa percobaan bunuh diri pada wanita ditemukan kebanyakan terkait dengan latar belakang broken home dan pelecehan/kekerasan seksual di masa kecil.

Perilaku bunuh diri meliputi tiga hal yaitu, suicide ideation (ide bunuh diri), suicide plan (rencana bunuh diri), dan suicide attempt (percobaan bunuh diri) dalam kerangka teori yang dikembangkan oleh Nock (2010). Self-injury tidak selalu terjadi pada orang dengan niat untuk bunuh diri meskipun menjadi salah satu bentuk perilaku bunuh diri. Keadaan ini disebut dengan non-suicidal self-injury (NSSI). NSSI adalah sebuah perilaku mencederai tubuh secara langsung dan disengaja dari jaringan tubuh seseorang tanpa adanya niat untuk bunuh diri (Nock, 2010). NSSI meliputi perilaku seperti mencabut rambut, memukul sendiri, memotong, mengukir kata atau gambar pada kulit, dan membakar (Klonsky, 2007).

Perilaku NSSI dikalangan remaja cukup mengkhawatirkan.Indriyani dan Hamidah (2020), menunjukkan sebanyak 69,5\% atau 429 dari 617 remaja pernah melakukan NSSI setidaknya satu kali dalam seumur hidupnya. Plener dan kawan-kawan (2018) menemukan prevalensi NSSI tertinggi terjadi pada individu berusia 15-17 tahun. Menurut studi meta-analisis, prevalensi seumur hidup rata-rata dari setidaknya satu kejadian NSSI di sampel remaja di seluruh dunia adalah 17,2\%, sedangkan untuk dewasa awal sebanyak 13,4\% dan dewasa akhir 5,5\% (Swannell dkk., 2014). Serupa dengan NSSI berulang, sampel sekolah menunjukkan sebanyak 12,25\% remaja melaporkan NSSI berulang. Hal ini menunjukkan bahwa perilaku NSSI lebih sering muncul pada remaja.

Penelitian telah menunjukkan bahwa ada hubungan antara struktur keluarga dan NSSI, dengan remaja yang terlibat dalam NSSI lebih sering tinggal dalam keluarga single-parent atau keluarga dengan 
perceraian dibandingkan mereka yang tinggal dalam keluarga dengan orang tua yang lengkap (Nixon, Cloutier, \& Jansson, 2008; Whitlock dkk, 2006; dalam Baetens dkk., 2014). Sebuah penelitian oleh Trujillo \& Servaty-Seib (2018) tentang parental absence dan perilaku NSSI, menghasilkan perilaku NSSI akan lebih mungkin terjadi bagi mereka yang pernah mengalami ketidakhadiran orang tua nonpermanen daripada mereka yang mengalami ketidakhadiran orang tua permanen. Tidak hadirnya orang tua dalam hidup individu mendorong munculnya perilaku NSSI.

Salah satu faktor dari munculnya perilaku NSSI yaitu ciri kepribadian seseorang menunjukkan bahwa dimensi psikopatologis lebih konsisten terkait dengan NSSI (Ferrara dkk., 2012). Selain borderline personality disorder (BPD), perilaku NSSI juga ditemukan berkaitan dengan gangguan kepribadian lainnya seperti paranoid personality disorder, avoidant personality disorder, dan narcissistic personality disorder. Ciri dari narcissistic personality disorder (NPD) merupakan harga diri yang bervariasi dan rentan, dengan upaya pengaturan melalui perhatian dan pencarian persetujuan, dan keagungan terbuka atau terselubung.

Narsisme terbagi menjadi dua konstruk, yaitu grandiose dan vulnerability. Individu dengan grandiose narcissism yang tinggi cenderung memandang diri mereka sebagai pusat perhatian, unik, dan tak tertandingi, dan mereka mengharapkan lingkungan mereka juga berpikir hal yang serupa (Morf \& Rhodewalt, 2001). Berbeda dengan grandiose narcissism, vulnerability narcissism cenderung menghadapi kepercayaan diri yang rapuh dengan terlibat dalam fantasi muluk untuk dikenal dan diakui (Talmon \& Ginzburg, 2018). Vulnerability narcissism juga dikenal dengan emosi, impaired self, rendahnya self-esteem, dan regulasi perilaku dalam menanggapi kegagalan peningkatan diri dan kurangnya pengakuan dan kekaguman dari orang lain pada dirinya (Dawood dkk., 2018). Individu dengan grandiose narcissism mungkin menunjukkan temperamen approach tingkat tinggi tetapi temperamen avoidant tingkat rendah. Individu dengan vulnerable narcissism mungkin menunjukkan sikap pendekatan dan temperamen menghindar yang tinggi (Thomaes dkk., 2009).

Penelitian yang dilakukan Dawood dan kawan-kawan (2018) tentang narcissism and non-suicidal selfinjury, didapatkan bahwa terdapat hubungan keterkaitan antara individu dengan pathological narcissism dan perilaku NSSI. Kedua konstruk dalam pathological narcissism yaitu grandiose dan vulnerability berhubungan dengan NSSI secara bervariasi termasuk terdapat keterkaitan pula dengan BDP. Setiap hitungan perilaku NSSI tertentu juga diregresikan pada narcissistic grandiosity, narcissistic vulnerability, dan borderline pathology secara bersamaan dalam model regresi rintangan. Greitemeyer \& Sagioglou (2021) juga telah melakukan sebuah penelitian untuk mendalami tentang prediktor dari perilaku NSSI dilihat dari kontribusi aspek benign masochism dan sifat Dark Tetrad. Hasil dari penelitian ini adalah terdapat hubungan positif antara narsisme sebagai salah satu sifat dari Dark Tetrad dan keterlibatan dalam NSSI yang lebih terlihat pada vulnerable narcissism daripada grandiose narcissism. (Nock dkk., 2006) juga menemukan pada remaja yang melakukan self-injury ditemukan memenuhi kriteria diagnostik untuk gangguan kepribadian patologis.

Remaja yang mengalami kondisi keluarga tidak utuh, atau sering disebut dengan broken home, seringkali mengalami trauma emosional pada dirinya karena hal tersebut. Trauma emosional yang dirasakan remaja broken home dapat dikaitkan dengan perilaku strategi coping yang dilakukan sebagai pengalihan dari emosi negatif dari trauma yang dialami. Narsistik sebagai pola kepribadian yang dimiliki seseorang bercirikan dengan kebutuhan ekstrim akan pengakuan atau kekaguman dari orang lain khususnya vulnerable narcissism, menunjukkan tanda depresi karena self-esteem yang rendah, yang disebabkan dari kurangnya pengakuan dari orang lain (Czarna dkk, 2018; dalam Sauls \& Zeigler-Hill, 2020). Dengan itu, penelitian ini memiliki dua hipotesis, yaitu Ho: tidak terdapat pengaruh kecenderungan narsistik terhadap perilaku non-suicidal self-injury pada remaja broken home, dan Ha: terdapat pengaruh kecenderungan narsistik terhadap perilaku non-suicidal self-injury pada remaja

Buletin Riset Psikologi dan Kesehatan Mental (BRPKM)

2021, Vol. 1(1), 87-95 
broken home. Tujuan dari penelitian ini adalah untuk menguji secara empiris pengaruh kepribadian narsistik terhadap perilaku non-suicidal self-injury pada remaja yang mengalami broken home.

\section{Desain Penelitian}

\section{E T O D E}

Penelitian ini menggunakan pendekatan kuantitatif-eksplanatori dengan metode pengambilan data survei. Subjek penelitian akan diberikan pertanyaan terkait dengan variabel ukur yang akan diberikan menggunakan kuesioner.

\section{Partisipan}

Partisipan dalam penelitian ini adalah remaja laki-laki dan perempuan berusia 12-22 tahun yang mengalami kondisi keluarga broken home dengan rincian kriteria seperti orang tua telah bercerai, orang tua yang tidak hadir dalam kehidupan subjek, hilangnya peran dari salah satu atau kedua orang tua, dan kondisi keluarga yang tidak harmonis seperti terjadinya pertengkaran terus-menerus, kekerasaan verbal dan/atau fisik, dan lain-lain. Partisipan dalam penelitian ini juga merupakan seseorang yang pernah melakukan non-suicidal self-injury dalam hidupnya. Jumlah partisipan dalam penelitian ini adalah 135 partisipan ( $\mathrm{M}_{\text {usia }}=19,02 ; \mathrm{SD}_{\text {usia }}=2,33 ; 88,1$ persen perempuan).

Teknik sampling yang digunakan dalam penelitian ini adalah teknik purposive sampling karena penelitian ini membutuhkan kriteria khusus dalam pencarian subjek agar hasil yang didapat sesuai dengan tujuan penelitian. Penelitian ini menggunakan bantuan program G*Power untuk penentuan jumlah sampel. Penentuan jumlah sampel dilakukan menggunakan a priori: compute required sample size menghasilkan ukuran efek (Cohen $\mathrm{f}^{2}$ ) sebesar 0,15, nilai $\alpha$ sebesar 0,05 , dan power (1- $\beta$ ) sebesar 0,95 pada jumlah prediktor sebanyak 1 . Perhitungan ini mendapatkan hasil sampel yang dibutuhkan minimal yaitu sebanyak $\mathrm{N}=85$.

\section{Pengukuran}

Penelitian ini menggunakan Pathological Narcissism Inventory (PNI) yang dikembangkan oleh Pincus dan kawan-kawan (2009) untuk mengukur variabel kepribadian narsistik. PNI memiliki total 52 aitem dengan 7 pilihan jawaban $(0=$ 'sangat tidak seperti saya', $6=$ 'sangat seperti saya'), yang berbentuk kuesioner self-report dan sudah ditranslasi ke Bahasa Indonesia. PNI memiliki reliabilitas alat ukur yang cukup baik $(\alpha=0,91)$. Variabel perilaku non-suicidal self-injury diukur menggunakan Inventory of Statements About Self-injury (ISAS) yang berjumlah 39 aitem, dengan tambahan 1 aitem sebagai item pecahan (Klonsky \& Glenn, 2009). ISAS merupakan skala self-report yang sudah ditranslasi ke Bahasa Indonesia. Pilihan jawaban pada skala ini terdiri dari 3 pilihan jawaban $(0=$ 'tidak relevan', $2=$ 'sangat relevan'). ISAS memiliki reliabilitas yang baik $(\alpha=0,88)$.

Pembuktian hipotesis penelitian dilakukan uji regresi. Sebelumnya dilakukan uji asumsi parametrik yaitu uji normalitas, uji linearitas, dan uji heterokedastisitas. Data berdistribusi normal dan terdapat hubungan yang linear antara kedua variabel. Pengamatan terhadap pola scatterplot menunjukkan tidak adanya gejala heteroskedastisitas.

\section{Analisis Data}

Uji korelasi dan uji regresi dilakukan menggunakan software IBM SPSS Statistic 22.00 for Mac. Uji regresi berganda dilakukan untuk melihat perbedaan tingkat pengaruh dari dua konstruk kepribadian narsistik

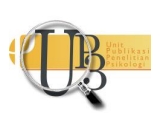


terhadap perilaku non-suicidal self-injury. Analisis tambahan uji beda juga dilakukan, yaitu independent $t$-test dan one-way anova berdasarkan data demografis dari partisipan.

\section{HAS IL PENELITIAN}

Hasil uji analisis korelasi dengan bivariate pearson menunjukkan adanya hubungan positif antara variabel kepribadian narsistik dan perilaku NSSI pada remaja broken home $(\mathrm{r}(135)=0,343 ; \mathrm{p}=0,00)$. Uji korelasi juga menunjukkan bahwa vulnerability narcissism memiliki hubungan positif dengan perilaku NSSI $(r(135)=0,384 ; p=0,00)$, namun tidak pada grandiose narcissism $(r(135)=0,159 ; p=0,065>0,05)$. Selanjutnya, hasil uji regresi menunjukkan adanya pengaruh yang signifikan dari kepribadian narsistik terhadap perilaku NSSI pada remaja broken home sebesar 11,8\% $\left(r^{2}=0,118 ; p=0,000\right)$. Uji regresi juga dilakukan pada kedua konstruk dari variabel kepribadian narsistik terhadap perilaku NSSI, yang menghasilkan hanya vulnerability narcissism memiliki pengaruh signifikan terhadap perilaku NSSI $\left(\mathrm{r}^{2}=\right.$ $0,152 ; \mathrm{p}=0,000)$, namun grandiose narcissism tidak memiliki pengaruh yang signifikan terhadap perilaku NSSI $\left(\mathrm{r}^{2}=0,152 ; \mathrm{p}=0,405\right)$.

Analisis tambahan dengan uji beda independent t-test dan one-way anova yang dilakukan pada faktor demografis partisipan menghasilkan tidak adanya perbedaan yang signifikan antara hampir seluruh faktor demografis seperti jenis kelamin pada variabel kepribadian narsistik $(\mathrm{t}(133)=-0,73 ; \mathrm{p}=0,942$; 95\% CI $[-17,27 ; 16,03])$ dan pada variabel perilaku NSSI $(\mathrm{t}(133)=-1,22 ; \mathrm{p}=0,222 ; 95 \% \mathrm{CI}[-10,67 ; 2,5]$, faktor demografis usia pada variabel narsistik $(F(9,125)=0,698 ; p=0,71)$ dan pada variabel perilaku $\operatorname{NSSI}(F(9,125)=0,546 ; p=0,838)$, dan faktor demografis domisili pada variabel kepribadian narsistik $(F(32,102)=0,709 ; p=0,866)$. Namun, ditemukan perbedaan yang signifikan antara faktor demografis domisili dan variabel perilaku NSSI $(F(32,102)=2,123 ; \mathrm{p}=0.02)$.

\section{I S K U S I}

Penelitian ini menunjukkan adanya hubungan yang signifikan antara narsistik dan perilaku NSSI. Hubungan positif ditunjukkan dengan semakin tinggi tingkat narsistik, maka semakin tinggi resiko perilaku NSSI. Penelitian ini juga menunjukkan adanya pengaruh kepribadian narsistik terhadap perilaku NSSI. Artinya, kepribadian narsistik mempengaruhi perilaku NSSI sebesar 11,8\% dan 88,2\% lainnya berasal dari faktor lain yang tidak diteliti. Hal ini membuktikan bahwa Ha dalam penelitian ini diterima.

Hal ini sejalan dengan penelitian sebelumnya milik Greitemeyer \& Sagioglou (2021) bahwa kepribadian naristik berpengaruh secara signifikan terhadap perilaku NSSI yang muncul pada remaja. Berdasarkan dua dimensi yang diuji, hasil menunjukkan bahwa hanya vulnerability narcissism yang memiliki hubungan dan pengaruh yang signifikan terhadap perilaku NSSI. Hasil penelitian ini juga sejalan dengan penelitian milik Dawood dan kawan-kawan (2018) tentang pathological narcissism dan perilaku NSSI pada remaja, bahwa narsistik memengaruhi munculnya perilaku NSSI pada seseorang, khususnya pada dimensi vulnerability narcissism yang lebih tinggi.

Mayoritas subyek penelitian ini berjenis kelamin perempuan $(88,1 \%)$. Hal ini sejalan dengan penelitian milik Bresin \& Schoenleber (2015) yang menyatakan bahwa kemungkinan terlibat dalam NSSI untuk perempuan lebih tinggi daripada untuk pria, diluar dari faktor kondisi broken home yang dialami keduanya. Subjek yang mengalami kondisi broken home pada penelitian ini mayoritas berusia 21 tahun $(25,2 \%)$ dan berdomisili di Jakarta $(20,7 \%)$. Kondisi broken home yang paling banyak dialami subjek adalah orang tua yang telah bercerai (36\%), diikuti dengan hilangnya peran dari salah satu dan kedua orang tua $(24,5 \%)$. Bentuk perilaku NSSI yang paling banyak dilakukan subjek adalah mencubit anggota tubuh hingga memar atau luka $(11,7 \%)$.

Buletin Riset Psikologi dan Kesehatan Mental (BRPKM)

2021, Vol. 1(1), 87-95 
Kondisi broken home yang tertinggi pada penelitian ini adalah perceraian orang tua. Hasil dari penelitian ini mendukung penelitian Nixon dan kawan-kawan bahwa remaja yang terlibat perilaku NSSI lebih sering tinggal dalam keluarga satu orang tua atau keluarga dengan perceraian (Baetens dkk., 2014). Didukung juga oleh penelitian Trujillo \& Servaty-Seib (2018) yang mengatakan bahwa parental absence atau ketidakhadiran orang tua menjadi faktor resiko yang memengaruhi munculnya perilaku NSSI.

Penelitian ini juga sejalan dengan temuan Dawood dan kawan-kawan (2018), yaitu kepribadian narsistik memengaruhi munculnya perilaku NSSI pada remaja. Hubungan dari kedua variabel ini dapat dijelaskan bahwa individu yang memiliki nilai tinggi dalam kepribadian narsistik cenderung mundur ke lingkungan personal mereka untuk mengatasi pengaruh negatif dan disregulasi yang terkait dengan cedera kepribadian narsistik (Pincus dkk., 2009).

Berdasarkan dua dimensi dari kepribadian narsistik yang diteliti yaitu grandiose narcissism dan vulnerability narcissism, ditemukan bahwa hanya dimensi vulnerability narcissism saja yang berpengaruh pada munculnya perilaku NSSI. Hal ini sejalan dengan penelitian Miller dan kawan-kawan (2010), bahwa seseorang dengan kepribadian narsistik terkait dengan upaya bunuh diri, tetapi hanya vulnerability narcissism yang terkait dengan perilaku NSSI. Efek kecil namun signifikan dari grandiose narcissism pada NSSI lebih baik dijelaskan dengan varians bersama dengan narsisme secara keseluruhan (Bandel \& Anestis, 2020). Vulnerable narcissism ditemukan berhubungan kuat dengan nonsuicidal self-injury pada penelitian Greitemeyer \& Sagioglou (2021) yang mengatakan bahwa kecenderungan narsistik untuk menjadi agresif seharusnya menumbuhkan kecenderungan untuk terlibat dalam NSSI, terutama individu dengan vulnerable narcissism yang umumnya dicirikan oleh rasa tidak aman dan harga diri yang rendah.

\section{S I M P U L A N}

Berdasarkan analisis data yang telah dilakukan, kesimpulan dari penelitian ini terdapat pengaruh dari kepribadian narsistik terhadap perilaku non-suicidal self-injury pada remaja broken home, dengan besar pengaruh sebesar $11,8 \%$ dan $88,2 \%$ lainnya berasal dari faktor lain yang tidak diteliti. Pengaruh dari kepribadian narsistik terhadap perilaku non-suicidal self-injury bersifat positif, sehingga apabila nilai kepribadian narsistik meningkat, maka perilaku non-suicidal self-injury pun juga meningkat. penelitian ini juga menemukan bahwa dari kedua dimensi pada kepribadian narsistik, yaitu grandiose narcissism dan vulnerability narcissism memiliki pengaruh yang beda pada perilaku non-suicidal self-injury, yang ditunjukkan hanya pada vulnerability narcissism terdapat pengaruh signifikan terhadap perilaku NSSI.

Adapun saran untuk penelitian selanjutnya yaitu diharapkan untuk memperluas cakupan pengambilan data responden dan untuk memperpanjang durasi pengambilan data. Hal ini juga terkait dengan jumlah responden yang akan mengisi kuesioner. Saran untuk remaja dengan kondisi keluarga broken home, disarankan untuk membentuk dan memulai hubungan baru dengan kerabat atau kelompok pertemanan. Hal ini dirasa penting untuk membantu remaja dengan kondisi keluarga broken home agar tidak merasa sendirian menghadapi masalah pribadinya. Untuk remaja pelaku NSSI, diharapkan menggunakan penelitian ini sebagai wawasan untuk penyebaran kesadaran untuk mencari strategi coping selain perilaku NSSI. Hal ini dapat dilakukan dengan memproyeksikan kepribadian narsistik yang dimiliki menjadi sesuatu positif seperti pada sosial media. Kemudian, untuk keluarga dan orang tua diharapkan paham dengan tugas dan perannya masing-masing dalam pembentukan karakter pada anak. Keluarga diharapkan dapat menjadi tempat aman dengan memberikan support kepada anak, terutama mereka dengan perilaku non-suicidal self-injury. 


\section{U CAPAN TERIMAKAS IH}

Terima kasih kepada Allah SWT, Papa, Mama, Adis, dan seluruh pihak yang membantu proses penelitian ini dengan semangat dan dukungan yang selalu diberikan sampai dengan penyelesaian penelitian ini.

\section{DEKLARASI POTENSI TERJADINYA KONFLIK KEPENTINGAN}

Debby Shira Chintia Dewi dan Atika Dian Ariana tidak bekerja, menjadi konsultan, memiliki saham, atau menerima dana dari perusahaan atau organisasi manapun yang mungkin akan mengambil untung dari diterbitkannya naskah ini.

\section{PUSTAKA ACUAN}

Angst, J., Hengartner, M. P., Rogers, J., Schnyder, U., Steinhausen, H. C., Ajdacic-Gross, V., \& Rössler, W. (2014). Suicidality in the prospective Zurich study: prevalence, risk factors and gender. European Archives of Psychiatry and Clinical Neuroscience, 264(7), 557-565. https://doi.org/10.1007/s00406-014-0500-1.

Astriyani, Triyono, \& Hitipeuw, I. (2018). Hubungan Motivasi Belajar dan Tindakan Guru dengan Prestasi Belajar Siswa dengan Latar Belakang Broken Home Kelas V Sekolah Dasar. Jurnal Pendidikan: Teori, Penelitian, Dan Pengembangan, 3(6), 806-809. http://journal.um.ac.id/index.php/jptpp/article/view/11220/5363.

Baetens, I., Claes, L., Martin, G., Onghena, P., Grietens, H., Van Leeuwen, K., Pieters, C., Wiersema, J. R., \& Griffith, J. W. (2014). Is Nonsuicidal Self-Injury Associated With Parenting and Family Factors? Journal of Early Adolescence, 34(3), 387-405. https://doi.org/10.1177/0272431613494006.

Bandel, S. L., \& Anestis, M. D. (2020). Non-suicidal self-injury among male service members: Descriptive information and a preliminary examination of external correlates. Psychiatry Research, 285(August 2019), 112815. https://doi.org/10.1016/j.psychres.2020.112815.

Bresin, K., \& Schoenleber, M. (2015). Gender differences in the prevalence of nonsuicidal self-injury: A meta-analysis. Clinical Psychology Review, 38, 55-64. https://doi.org/10.1016/j.cpr.2015.02.009.

Dawood, S., Schroder, H. S., Donnellan, M. B., \& Pincus, A. L. (2018). Pathological narcissism and nonsuicidal self-injury. Journal of Personality Disorders, 32(1), 87-108. https://doi.org/10.1521/pedi_2017_31_291.

Ferrara, M., Terrinoni, A., \& Williams, R. (2012). Non-suicidal self-injury (Nssi) in adolescent inpatients: Assessing personality features and attitude toward death. Child and Adolescent Psychiatry and Mental Health, 6, 1-8. https://doi.org/10.1186/1753-2000-6-12.

Greitemeyer, T., \& Sagioglou, C. (2021). Predictors of nonsuicidal self-injury: The independent contribution of benign masochism and antisocial personality. Personality and Individual Differences, 168(August 2020), 110380. https://doi.org/10.1016/j.paid.2020.110380.

Indriyani, A., \& Hamidah. (2020). Pengaruh Kualitas Hubungan Pertemanan terhadap Kecerdasan Emosi pada Remaja Pelaku Non-suicidal Self-injury. Jurnal Psikologi Klinis dan Kesehatan Mental.

Klonsky, E. D. (2007). The functions of deliberate self-injury: A review of the evidence. Clinical Psychology Review, 27(2), 226-239. https://doi.org/10.1016/j.cpr.2006.08.002.

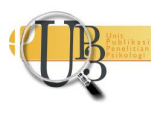


Klonsky, E., \& Glenn, C. (2009). Assessing the Functions of Non-suicidal Self-injury: Psychometric Properties of the Inventory of Statements About Self-injury (ISAS). Journal of Psychopathology and Behavioral Assess , 215-219.

Miller, J. D., Dir, A., Gentile, B., Wilson, L., Pryor, L. R., \& Campbell, W. K. (2010). Searching for a Vulnerable Dark Triad: Comparing Factor 2 Psychopathy, Vulnerable Narcissism, and Borderline Personality Disorder. Journal of Personality, 78(5), 1529-1564. https://doi.org/10.1111/j.14676494.2010.00660.x.

Morf, C. C., \& Rhodewalt, F. (2001). Unraveling the paradoxes of narcissism: A dynamic self-regulatory $\begin{array}{llll}\text { processing } \quad \text { model. } & \text { Psychological 12(4), }\end{array}$ https://doi.org/10.1207/S15327965PLI1204_1.

Nock, M. K. (2010). Self-Injury. Annual Review of Clinical Psychology, 6, 339-363. https://doi.org/10.1146/annurev.clinpsy.121208.131258.

Nock, M. K., Joiner, T. E., Gordon, K. H., Lloyd-Richardson, E., \& Prinstein, M. J. (2006). Non-suicidal selfinjury among adolescents: Diagnostic correlates and relation to suicide attempts. Psychiatry Research, 144(1), 65-72. https://doi.org/10.1016/j.psychres.2006.05.010.

Pincus, A. L., Ansell, E. B., Pimentel, C. A., Cain, N. M., Wright, A. G. C., \& Levy, K. N. (2009). Initial Construction and Validation of the Pathological Narcissism Inventory. Psychological Assessment, 21(3), 365-379. https://doi.org/10.1037/a0016530.

Plener, P. L., Kaess, M., Schmahl, C., Pollak, S., Fegert, J. M., \& Brown, R. C. (2018). Non-suicidal self-injury in adolescents. Deutsches Arzteblatt International, 115(3), 23-30. https://doi.org/10.3238/arztebl.2018.0023.

Sauls, D., \& Zeigler-Hill, V. (2020). Basic emotional systems and narcissistic personality features: What is the emotional core of narcissism? Personality and Individual Differences, 162(April), 110032. https://doi.org/10.1016/j.paid.2020.110032.

Schaller, S., \& Schmidtke, A. (1988). Broken Home and Suicidal Behavior: Methodological Problems. Current Issues of Suicidology, 279-295. https://doi.org/10.1007/978-3-642-73358-1_38.

Swannell, S. V., Martin, G. E., Page, A., Hasking, P., \& St John, N. J. (2014). Prevalence of nonsuicidal selfinjury in nonclinical samples: Systematic review, meta-analysis and meta-regression. Suicide and Life-Threatening Behavior, 44(3), 273-303. https://doi.org/10.1111/sltb.12070.

Talmon, A., \& Ginzburg, K. (2018). The Differential Role of Narcissism in the Relations Between Childhood Sexual Abuse, Dissociation, and Self-Harm. Journal of Interpersonal Violence. https://doi.org/10.1177/0886260518799450.

Thomaes, S., Bushman, B. J., Orobio De Castro, B., \& Stegge, H. (2009). What makes narcissists bloom? A framework for research on the etiology and development of narcissism. Development and Psychopathology, 21(4), 1233-1247. https://doi.org/10.1017/S0954579409990137.

Trujillo, N. P., \& Servaty-Seib, H. (2018). Parental Absence and Non-Suicidal Self-Injury: Social Support, Social Constraints and Sense-Making. Journal of Child and Family Studies, 27(5), 1449-1459. https://doi.org/10.1007/s10826-017-0976-1.

Willis, S. S. (2015). Konseling keluarga (family counseling). Penerbit Alfabeta: Bandung.

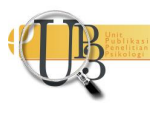


Zatti, C., Rosa, V., Barros, A., Valdivia, L., Calegaro, V. C., Freitas, L. H., Ceresér, K. M. M., Rocha, N. S. da, Bastos, A. G., \& Schuch, F. B. (2017). Childhood trauma and suicide attempt: A meta-analysis of longitudinal studies from the last decade. Psychiatry Research, 256, 353-358. https://doi.org/10.1016/j.psychres.2017.06.082 